\title{
Current paradigms and evolving concepts in metastatic castration-resistant prostate cancer
}

\begin{abstract}
Sumanta Kumar $\mathrm{Pal}^{1}$ and Oliver Sartor ${ }^{2}$
Until recently, docetaxel-based therapy represented the only therapy shown to prolong survival in patients with metastatic castration-resistant prostate cancer (mCRPC). The past year and a half has been marked by unprecedented progress in treatments for this disease. Three positive phase III clinical trials have emerged, each evaluating agents (sipuleucel-T, cabazitaxel and abiraterone) with distinct mechanisms of action. Herein, the three pivotal trials are described alongside both past and current large phase III studies conducted in this mCRPC. The overall survival for patients with MCRPC treated in current clinical trials is considerably longer than noted in the past. We note that more recent trials with older agents have also shown improved survival and discuss potential non-therapeutic biases that influence this critical measure of outcome. The necessity for utilizing randomized trials when evaluating new therapeutics is emphasized given the changing prognosis in this mCRPC.
\end{abstract}

Asian Journal of Andrology (2011) 13,683-689; doi:10.1038/aja.2011.35; published online 23 May 2011

Keywords: abiraterone; bevacizumab; cabazitaxel; castrate resistant; castration resistant; docetaxel; hormone refractory; Jevtana; Provenge; prostate cancer; sipuleucel-T

\section{INTRODUCTION}

In 2010, an estimated 217730 cases of prostate cancer were diagnosed in the United States, accounting for $28 \%$ of new cancers in men. ${ }^{1}$ Although these numbers are remarkable, the peak incidence was observed in the earlier half of the last decade when widespread prostate-specific antigen (PSA) screening was introduced for the first time. Annual age-adjusted prostate cancer death rates have declined over the past several years. ${ }^{2}$ The root causes of these trends are multifold. Adoption of PSA screening has led to a dramatic increase in the incidence of asymptomatic low-risk disease as shown in prospective randomized trials. ${ }^{3-5}$ The increased use of PSA has led to a drastic stage migration, with only a small proportion of patients now presenting with metastatic disease in the United States. ${ }^{6}$ Therapies for localized prostate cancer have been refined, not only through novel surgical and radiation-based modalities, but also through additions of adjuvant androgen-deprivation therapy in selected setting. ${ }^{7,8}$ The collective effects of these therapeutic efforts have likely contributed to the declining rates of prostate cancer-related death.

Until recently, it was challenging to argue that advances in the management of metastatic castration-resistant prostate cancer (mCRPC) were significantly altering survival (Table 1). The first chemotherapy regimen approved for $\mathrm{MCRPC}$, mitoxantrone at $12 \mathrm{mg} \mathrm{m}^{-2}$ with prednisone, was adopted on the basis of palliative benefit in a National Cancer Institute (NCI) Canada trial. This study randomized 161 patients with symptomatic CRPC to mitoxantrone and prednisone or prednisone alone from August 1990 to April 1994. ${ }^{9}$ The study failed to meet several secondary end points, including overall survival (OS). A subsequent Cancer and Leukemia Group B
(CALGB) study produced similar results. ${ }^{10}$ In CALGB 9182, 242 patients were randomized to either mitoxantrone with hydrocortisone or hydrocortisone alone. Again, mitoxantrone rendered no benefit with respect to OS.

Mitoxantrone and prednisone became a standard of care for mCRPC and comprised the comparator arm in two subsequent pivotal studies evaluating docetaxel. ${ }^{11,12}$ First, in the TAX 327 trial, a total of 1006 men were randomized March 2000 through June 2002 to receive either docetaxel at one of two schedules or mitoxantrone at $12 \mathrm{mg} \mathrm{m}^{-2}$; all arms contained $10 \mathrm{mg}$ of daily oral prednisone. ${ }^{13}$ Treatment with docetaxel on a 21-day cycle at $75 \mathrm{mg} \mathrm{m}^{-2}$ was associated with an improvement in median OS (19.2 months vs. 16.3 months, $P=0.004)$. The benefit with docetaxel was noted across various subgroups categorized by age, baseline pain symptoms and baseline PSA. Second, Southwest Oncology Group (SWOG) trial 9916 randomized 674 patients to receive either docetaxel and estramustine or mitoxantrone and prednisone with enrollment between October 1999 and January 2003. As in TAX 327, the results of SWOG 9916 identified a survival advantage associated with docetaxel therapy (17.5 months vs. 15.6 months, $P=0.02) .{ }^{14}$ Progression-free survival was 6.3 months in the docetaxel containing arm as compared to 3.2 months.

It is important to note that the NCI Canada trial of mitoxantrone reported a median OS of 10.8 months. Less than a decade later, the TAX 327 study reported a median survival for mitoxantrone at the same dose and schedule of 16.3 months (Table 1). It is critical to appreciate that the differences in survival for the mitoxantronecontaining arms across time was considerably numerically higher than the differences between the mitoxantrone and docetaxel arms

${ }^{1}$ Division of Genitourinary Malignancies, Department of Medical Oncology and Experimental Therapeutics, City of Hope Comprehensive Cancer Center, Los Angeles, CA, USA and

${ }^{2}$ Tulane University School of Medicine, New Orleans, LA, USA

Correspondence: Dr SK Pal (spal@coh.org)

Received: 21 January 2010; Revised: 6 March 2010; Accepted: 11 March 2011; Published online: 23 May 2011 
Table 1 Pivotal trials in the treatment of metastatic castration-resistant prostate cancer (mCPRC) and associated median survival data

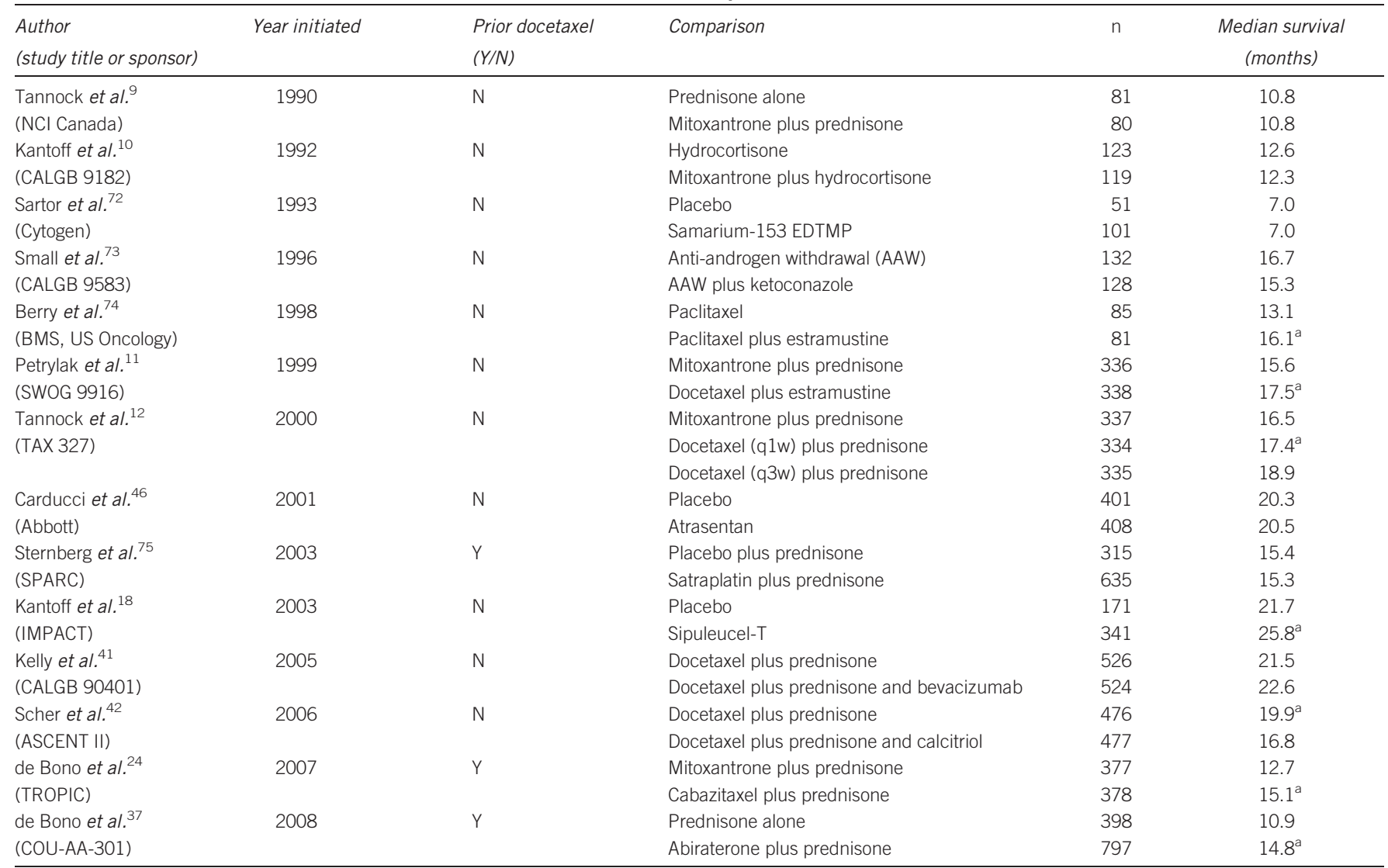

a Overall survival advantage $(P<0.05)$ associated with the respective treatment arm.

in TAX 327. This is likely due to the treatment of less symptomatic patients in the TAX 327 study as compared to the NCI Canada trial and emphasizes that patient selection may be just as important as therapeutic choices in the prognosis of patients with MCRPC.

Within the past year and a half, landmark developments in prostate cancer have added additional insights for patients with mCRPC. A diverse array of new agents has been added to the arsenal of therapies shown to prolong survival for mCRPC, including a novel cytotoxic (cabazitaxel), a dendritic cell vaccine (sipuleucel-T) and a novel androgen synthesis inhibitor (abiraterone). Herein, we provide an overview of these important new agents and discuss them in the context of evolving survival data associated with mCRPC patients over the past decade.

\section{A DENDRITIC CELL VACCINE FOR PROSTATE CANCER: SIPULEUCEL-T}

Sipuleucel-T is an autologous cellular immunotherapy derived from host peripheral blood mononuclear cells activated by a recombinant fusion protein (PA2024) comprised of prostatic acid phosphatase fused to granulocyte-macrophage colony-stimulating factor (GMCSF). The agent has undergone a complex evolution while on its course for approval in the setting of CRPC. In an early phase III study (D9901), 127 patients with asymptomatic mCRPC were randomized in a $2: 1$ fashion to receive sipuleucel-T or a series of non-activated cells (placebo), respectively. ${ }^{15}$ Patients were offered a cryopreserved product at the time of disease progression. The primary end point of the study (time to progression, TTP) was not met. However, there was a benefit in OS with sipuleucel-T prolonging survival by 4.5 months compared to placebo (25.9 months vs. 21.4 months, $P=0.01$ ). When results of a second similar study (D9902A) that had 98 patients enrolled was combined with the results of D9901, survival benefit observed with sipuleucel-T was preserved (23.2 months vs. 18.9 months, $P=0.011) .{ }^{16}$ Although the OS advantage seen with sipuleucel-T in D9901 and D9902A leads to an initial US FDA filing, the results were criticized in light of the small number of patients on the initial trials and a failure to demonstrate an improvement in the primary study end point, TTP. ${ }^{17}$

Responding to these critiques, the larger D9902B study utilized a similar 2:1 randomization of sipuleucel-T to placebo, but employed OS as the primary end point and included a total of 512 patients. ${ }^{18}$ Eligibility criteria required $\mathrm{mCRPC}$ patients that were asymptomatic or minimally symptomatic, an important distinction to note. The study also excluded patients with visceral metastases which have been linked to poor prognosis. The majority of patients enrolled had a low Gleason score $(\leqslant 7,75 \%)$ and only a small proportion had received prior chemotherapy $(19.6 \%)$. More than $80 \%$ of patients had an Eastern Cooperative Oncology Group performance status of zero. As in D9901 and D9902A, a benefit in OS but not TTP was observed (OS of 25.8 months vs. 21.7 months, $P=0.03$ ). Of note the control group lived longer than docetaxel treated patients in the TAX 327 study. On the basis of the D9901, D9902A and D9902B data, sipuleucel-T was granted approval by the US FDA in April 2010. ${ }^{19}$

The lack of improvement in TTP in all studies of sipuleucel-T therapy may imply that the time to utilization of docetaxel and other subsequent therapies could remain constant, although this requires 
further assessment. Although a median OS of 25.8 months is encouraging, differences in the study population at trial enrollment make it inappropriate to directly compare sipuleucel-T to modalities such as docetaxel. It has long been known that symptoms influence survival and the high percentage of patients with an excellent performance status (Eastern Cooperative Oncology Group performance status of 0 ) needs to be kept in mind when interpreting longevity. In evaluating immunotherapy, a novel set of response criteria has been proposed based on experience with the CTLA4-directed monoclonal antibody ipilimumab. ${ }^{20}$ These criteria acknowledge four specific response patterns associated with the agent, including (i) shrinkage in baseline lesions without the occurrence of new lesions; (ii) durable stable disease; (iii) response in new lesions that are incurred; and (iv) response after an increased in overall tumor burden occurs. Utilizing the collective experience of immune-modulating agents to establish novel response criteria may be necessary as these treatments move to the forefront of cancer therapy. It remains to be seen whether such guidelines will be applicable to agents such as sipuleucel-T, however.

Ultimately, it would be prudent to identify biomarkers that may predict response to sipuleucel-T. However, at present, the immune effects of the drug have not been fully characterized. Sheikh et al. recently presented data correlative studies paired with phase III clinical trials of sipuleucel-T. ${ }^{21}$ At the time of each leukapheresis, a proportion of peripheral blood mononuclear cells were sequestered and stimulated with GM-CSF. In contrast to these cells, sipuleucel-T (i.e., peripheral blood mononuclear cells stimulated with PA2024) had increased antigen-presenting cell activation-associated cytokines (IL$1 \alpha$, IL-10, IL-12 and TNF- $\alpha$ ) and T-cell activation-associated cytokines (IL-2, IL-4, IL-5, IL-6, IL-10, IL-13, IFN- $\gamma$ and TNF- $\alpha$ ). The rather broad scope of the PA2024-induced cytokine response makes it challenging to identify a specific marker of activity. Future studies are challenged with defining a panel of moieties that serve such a role.

\section{A NOVEL TAXANE FOR CRPC: CABAZITAXEL}

The preclinical activity of cabazitaxel was first reported nearly a decade ago, with low inhibitory concentrations noted across multiple cell lines $\left(\mathrm{IC}_{50}=3-29 \mathrm{ng} \mathrm{ml}{ }^{-1}\right){ }^{22}$ A subsequent phase I clinical trial enrolled 25 patients with advanced solid tumors, including eight patients $(32 \%)$ with prostate cancer. ${ }^{23}$ On the basis of the preclinical and phase I data, a phase III trial (TROPIC) was initiated for patients with $\mathrm{mCRPC}$ who progressed despite prior docetaxel therapy. ${ }^{24}$ Patients were randomized to receive up to 12 cycles of cabazitaxel $\left(25 \mathrm{mg} \mathrm{m}^{-2}\right)$ with prednisone or mitoxantrone $\left(12 \mathrm{mg} \mathrm{m}^{-2}\right)$ with prednisone between January 2007 and October 2008. Failure of prior docetaxel was defined for non-measurable disease by the presence of two consecutive PSA rises or appearance of new lesion and for measurable disease by Response Evaluation Criteria in Solid Tumors.

A total of 755 patients were ultimately randomized on the TROPIC study, with a median age of 68 years and a median of seven prior cycles of docetaxel. ${ }^{24}$ The vast majority of patients had an Eastern Cooperative Oncology Group performance status of $0-1(92 \%) .{ }^{20}$ The trial met its primary end point of OS with an improvement from 12.7 months with mitoxantrone to 15.1 months with cabazitaxel $(P<0.0001)$. In analyses of subgroups, the benefit of cabazitaxel appeared to be relatively consistent. Survival analyses favored cabazitaxel in groups based on baseline pain status, the number of prior cytotoxic agents rendered, age and performance status. These encouraging results have led to the design of a new phase III clinical trial that will compare two doses of cabazitaxel therapy $\left(20\right.$ or $\left.25 \mathrm{mg} \mathrm{m}^{-2}\right)$ to docetaxel at standard doses $\left(75 \mathrm{mg} \mathrm{m}^{-2}\right)$ as initial chemotherapy for patients with mCRPC. ${ }^{25}$
With respect to quality of life-driven end points, cabazitaxel did not lead to a significant improvement in the time to pain progression. Notable toxicities associated with cabazitaxel in the TROPIC study include neutropenia-grade $>3$ neutropenia occurred in $82 \%$ of patients, with a further $8 \%$ of patients developing febrile neutropenia. Importantly, seven patients (2\%) receiving cabazitaxel therapy died of neutropenic complications. ${ }^{24}$ The most common non-hematological toxicities (grade 3 or worse) incurred with cabazitaxel were diarrhea $(6 \%)$, fatigue $(5 \%)$ and asthenias $(5 \%)$. Of note, five patients $(1 \%)$ died of cardiac causes.

It is important to note that mitoxantrone in the post-docetaxel mCRPC setting had a longer survival than did the initial randomized NCI Canada study in the 'first-line' setting (Figure 1a). The reason for this is probably in part due to the earlier use of first-line chemotherapy (a form of lead time bias) and the selection in the TROPIC trial for good performance status patients with good organ function. Given that not all patients with post-docetaxel progression would have qualified for TROPIC, it is important to remember that survival in clinical trial settings always reflects a selected subset of the more general population. The number of patients who would be eligible for second-line chemotherapy post-docetaxel has yet to be accurately ascertained.

\section{TARGETING HORMONAL AXES IN HORMONE-RESISTANT DISEASE: ABIRATERONE}

Since the pivotal observations of Huggins in 1941, the role of castration in prostate cancer therapy has been well established. ${ }^{26,27}$ Over the past several decades, surgical castration has been largely supplanted by pharmacological interventions, including leutenizing hormone releasing
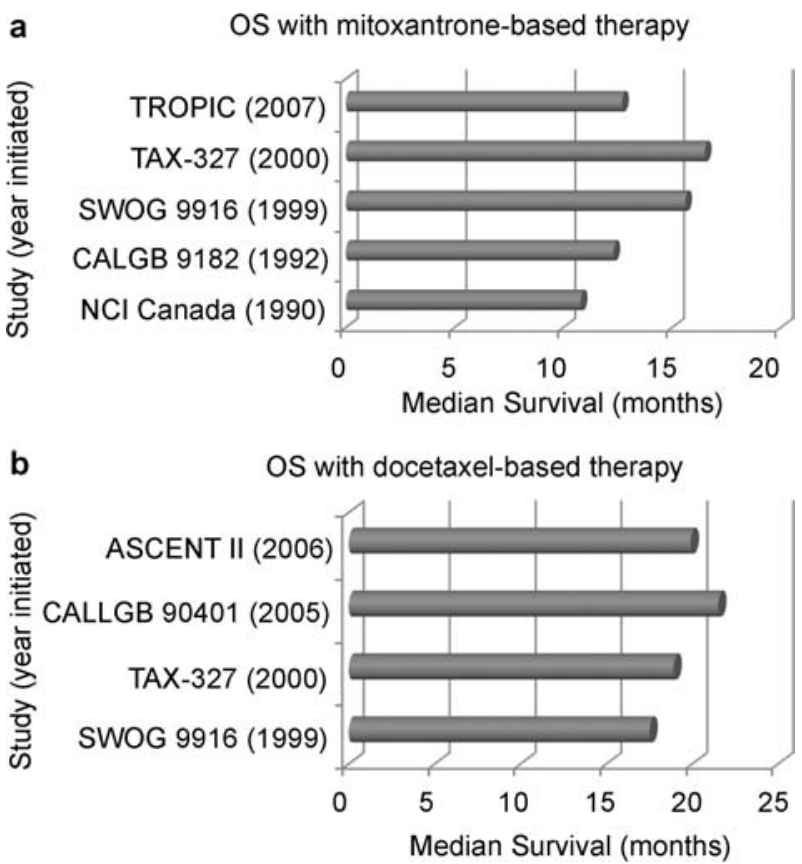

Figure 1 Trends in survival with mitoxantrone-based (a) and docetaxel-based (b) therapies in phase III trials in castration-resistant prostate cancer (CPRC). (a) Overall survival (OS) with mitoxantrone-based therapy in five pivotal studies. Note that survival in the TROPIC trial exceeded that in the earlier CALGB 9182 and $\mathrm{NCI}$ Canada efforts, despite the fact that TROPIC included CRPC patients that had progressed on docetaxel. (b) OS with docetaxel-based therapy in four pivotal studies. Akin to the data for mitoxantrone, note that more recent efforts (CALGB 90401 and ASCENT II) yielded increased survival with docetaxel-based therapy as compared to older studies (SWOG 9916 and TAX-327). 
hormone analogs and antiandrogens. ${ }^{28-30}$ In contrast to these agents, abiraterone is an irreversible inhibitor of CYP17, blocking two critical steps in testosterone biosynthesis: conversion of pregnenolone to ${ }^{17} \mathrm{OH}$-pregnenolone, and conversion of ${ }^{17} \mathrm{OH}$-pregnenolone to dihydroepiandrostenedione. ${ }^{31,32}$ Subsequent clinical trials of abiraterone established activity in both chemotherapy-naive and docetaxel pretreated patients. ${ }^{33-36}$

Encouraging data from these earlier studies prompted phase III efforts exploring abiraterone in $\mathrm{mCRPC}$ patients. The phase III COU-AA-301 study was first reported in October 2010 in abstract form, randomizing 1195 patients with docetaxel-refractory CRPC in a 2:1 fashion to either abiraterone/prednisone or placebo/prednisone. ${ }^{37}$ The use of prednisone alone as the control group emphasizes the lack of consensus for what had constituted 'standard' of care in the post-docetaxel setting at the time the trial was initiated. The median age of the study population was 69 years, and majority of patients had received one prior cytotoxic agent $(72 \%)$. The primary end point of the study was OS, and abiraterone led to an improvement in this measure (14.8 months vs. 10.4 months, $P<0.0001$ ). With respect to secondary end points, abiraterone also led to an improvement in radiographic progression-free survival (5.6 months vs. 3.6 months, $P<0.0001)$ and PSA response rate $(29.1 \%$ vs. $5.5 \%, P<0.0001)$. Although a Brief Pain Inventory was performed at baseline, no report of pain-related outcomes is available at this time. Therapy with abiraterone was well tolerated, and in fact, the frequency of adverse events among patients receiving placebo exceeded the frequency among patients receiving abiraterone. The most common grade 3 or 4 toxicities associated with abiraterone included fluid retention (2.3\%), hypokalemia $(3.8 \%)$, hypertension (1.3\%) and cardiac disorders (4.1\%).

Akin to the TROPIC trial evaluating cabazitaxel, the COU-AA-301 results render abiraterone a viable option in the MCRPC beyond docetaxel, further extending the timeline of anticipated survival in CRPC patients. As with cabazitaxel, current efforts may push abiraterone forward in the current treatment paradigm. An ongoing phase III clinical trial randomizing asymptomatic or mildly symptomatic chemotherapy-naive mCRPC patients to either abiraterone/prednisone or prednisone/placebo has recently completed accrual with interim analyses for progression expected in $2011 .^{38}$ Additional phase II efforts are exploring abiraterone in the setting of localized disease, either as neo-adjuvant therapy prior to prostatectomy or in combination with definitive radiation therapy. ${ }^{39-40}$ As results from these studies emerge, the utilization of abiraterone therapy is subject to drastic change. It is likely that abiraterone will move ahead of chemotherapeutic regimens in the overall treatment paradigm as evolving data support that concept.

\section{CURRENT AREAS OF RESEARCH IN CRPC THERAPY}

\section{Building on docetaxel}

The aforementioned pivotal studies of sipuleucel-T, cabazitaxel and abiraterone have all reported positive OS data within the past year. However, these studies represent only a fraction of the phase III evaluations either ongoing or recently completed in mCRPC. Several studies are investigating the combination of docetaxel with a range of therapeutics. The highly anticipated CALGB 90401 trial randomized 1050 chemotherapy-naive mCRPC patients to docetaxel with either bevacizumab or placebo. ${ }^{41}$ No significant improvement in OS was observed (22.6 months with bevacizumab vs. 21.5 months with placebo, $P=0.18)$. The survival data were longer than anticipated in both groups (Figure 1b), underscoring the continuing improvement in survival in patients with $\mathrm{mCRPC}$ even when similar therapies are used. The control arm of (docetaxel at $75 \mathrm{mg} \mathrm{m}^{-2}$ every 21 days with prednisone) is analogous to experimental arm in the TAX 327 study, the latter reporting an OS of 19.2 months.

Disappointing results were also noted from the ASCENT II study, randomizing 953 men with CRPC to either weekly docetaxel, highdose calcitriol and dexamethasone, or every 21 day docetaxel at 75 $\mathrm{mg} \mathrm{m}^{-2}$ and prednisone, the latter representing the control group. ${ }^{42} \mathrm{At}$ the time of an interim analysis, more deaths were observed on the experimental arm. Median OS was superior on the control arm (19.9 months $v s .16 .8$ months, $P=0.019$ ), suggesting either the futility of weekly docetaxel or the negative effect of adding calcitriol to a docetaxel-based regimen.

It remains to be seen whether other current efforts to build upon docetaxel will meet with success. The endothelin A antagonist zibotentan showed promising activity in a relatively large randomized phase II study in mCRPC, but a recent press release for a phase III trial comparing single-agent zibotentan to placebo in patients with mCRPC indicated failure to meet the study's primary end point of OS-tempering enthusiasm for the agent. ${ }^{43}$ Nonetheless, phase III trials evaluating the combination of docetaxel and zibotentan have yet to be reported. ${ }^{44}$ A phase III SWOG trial of docetaxel with or without atrasentan (another endothelin antagonist) has also completed accrual in $2010 .{ }^{45}$ Mirroring the experience with zibotentan, a prior phase III evaluation comparing single-agent atrasentan to placebo failed to improve survival in mCRPC. ${ }^{46}$

Other notable current efforts in this domain include the phase III 'Mainsail' study, randomizing patients with chemotherapy-naive CRPC to docetaxel and prednisone with or without lenalidomide. ${ }^{47}$ In a phase I/II trial including patients with non-castrate, non-metastatic biochemically relapsed prostate cancer, treatment with lenalidomide led to PSA declines. ${ }^{48}$ A phase I study of paclitaxel and lenalidomide conducted in patients with taxane-refractory CRPC also demonstrated moderate activity. ${ }^{49}$ A phase III trial of docetaxel and prednisone with or without OGX-011 (a clusterin inhibitor) is now underway. ${ }^{50}$ The impetus for the study was a phase II effort exploring the same randomization in patients with mCRPC. ${ }^{51}$ With 82 patients accrued, therapy with OGX011 was associated with a non-statistically significant improvement in progression-free survival (7.3 months vs. 6.1 months), but OS was relatively prolonged (23.8 months $v s .16 .9$ months). These results have triggered a phase III trial which will be closely watched. A phase III trial with docetaxel/prednisone with or without dasatinib (a Src-directed compound) is also underway. Though little data support the use of dasatinib, this trial is also of considerable interest given the provocative mechanism of action.

\section{Novel vaccine therapies}

In contrast to the favorable results from the phase III evaluation of sipuleucel-T, phase III evaluations of GVAX have produced more sobering results. GVAX represents a cellular vaccine derived from PC-3 and LN-CaP prostate cancer cell lines modified to secrete GMCSF. ${ }^{52}$ The VITAL-1 study, initiated in 2004, randomized mCRPC patients to receive either GVAX or docetaxel with prednisone. ${ }^{53}$ The study was prematurely terminated based on a futility analysis. A total of 626 patients accrued, survival was 20.7 months with GVAX compared to 21.7 months with docetaxel and prednisone $(P=0.78)$. Generating subsets based on survival predicted by the Halabi nomogram, those patients with a predicted survival $\geqslant 18$ months appeared to have more substantial benefit from GVAX therapy; however, such subset analyses have generated little interest. ${ }^{54} \mathrm{~A}$ second large assessment of GVAX, the VITAL-2 study, was also prematurely terminated. 
A total of 408 patients with mCRPC were randomized to receive either docetaxel with prednisone or docetaxel with GVAX. ${ }^{55}$ At the time of preliminary analysis, more deaths were seen on the GVAX-containing arm (67 vs. 47). Ultimately, OS was noted to be prolonged in patients treated with docetaxel and prednisone, but these data have not been reported in mature datasets. Although VITAL-2 has been criticized for the omission of prednisone in the experimental arm, the overall results from clinical evaluations of GVAX have been negative, and it is unclear that it will be developed further in mCRPC.

In contrast to GVAX, encouraging data were reported from a randomized phase II study examining PROSTVAC-VF. ${ }^{56}$ The product encompasses three immunomodulators, B7.1, LFA-3 and ICAM-1, as well as two viral vectors encoding transgenes for PSA. In total, 125 patients with minimally symptomatic, chemotherapy-naive mCRPC were randomized 2:1 to receive either PROSTVAC-VF with GM-CSF or the control. As with sipuleucel-T, the agent conferred an improvement in OS (25.1 months vs. 16.1 months, $P=0.0061$ ) without any benefit in progression-free survival. This control group may have had a shorter than expected survival and phase III trials are clearly needed. A phase III trial of PROSTVAC is presently under development, but we note that future trials in MCRPC will be more complicated given the current availability of multiple therapies now shown to prolong survival.

\section{Novel endocrine therapies}

As the aforementioned studies illustrate, there have been mixed results from phase III evaluations of agents for mCRPC. Importantly, the agents described herein represent only a small fraction of those in the current pipeline. Among those with a promising phase I/II data is MDV3100, a non-steroidal antiandrogen with greater affinity for the androgen receptor than bicalutamide. ${ }^{57}$ Preclinical assessment of MDV3100 also suggests inhibition of nuclear translocation of androgen receptors. A phase I/II evaluation of the agent in 140 patients with mCRPC yielded a decrease in PSA $\geqslant 50 \%$ in 78 patients $(56 \%)$, with a median radiographic TTP of 47 weeks. ${ }^{58}$ MDV3100 is currently being compared to placebo in other trials evaluating both chemotherapynaive and docetaxel-refractory patients with CRPC. ${ }^{59,60}$

TAK-700 represents yet another novel endocrine therapy for prostate cancer. Like abiraterone, it inhibits CYP17 at low concentrations $\left(\mathrm{IC}_{50}=28 \mathrm{nmol}^{-1}\right){ }^{61}$ In a phase I/II study assessing TAK-700 (with or without prednisone) in 26 patients with metastatic CRPC, all patients dosed above a certain threshold ( $\geqslant 300 \mathrm{mg}$ oral bid) experienced a decline in PSA. ${ }^{62}$ In a subset of 15 evaluable patients receiving TAK700 doses above this threshold, PSA reductions of $\geqslant 50 \%$ and $\geqslant 90 \%$ were seen in $12(80 \%)$ and $4(27 \%)$ patients, respectively. Phase III efforts are now assessing prednisone with either TAK-700 or placebo in men with mCRPC. ${ }^{63}$

\section{CONCLUSIONS}

Key results for multiple studies in $\mathrm{MCRPC}$ are pending, and each dataset has significant implications for the current treatment algorithm of prostate cancer. For instance, if pivotal studies of MDV3100 are positive post-docetaxel, it will be a challenge to ascertain whether the agents should be sequenced before or after abiraterone or cabazitaxel. We know little about how MDV3100 will perform in patients previously treated with abiraterone and this is an important consideration in designing future trials. Likewise, if larger trials of PROSTVAC-VF show benefit in the chemotherapy-naive setting, is there benefit in addition to sipuleucel-T therapy? Figure 2 summarizes several key ongoing questions in mCRPC clinical research. Moving forward, it will be necessary to address the issues of sequences, combinations and cross-resistance in a logical fashion. Randomized trials are essential given the changing natural history of the disease as pointed out above. Disentangling science and corporate interests is likely to be difficult as multiple agendas will be at the table.

Considerable attention has been focused on biomarkers in recent years. As one prominent example of this, PSA characteristics (baseline PSA, PSA doubling time and PSA decline within 3 months of therapy) have been shown to stratify outcomes with docetaxel chemotherapy in the pivotal TAX327 study. ${ }^{64}$ Several examples of

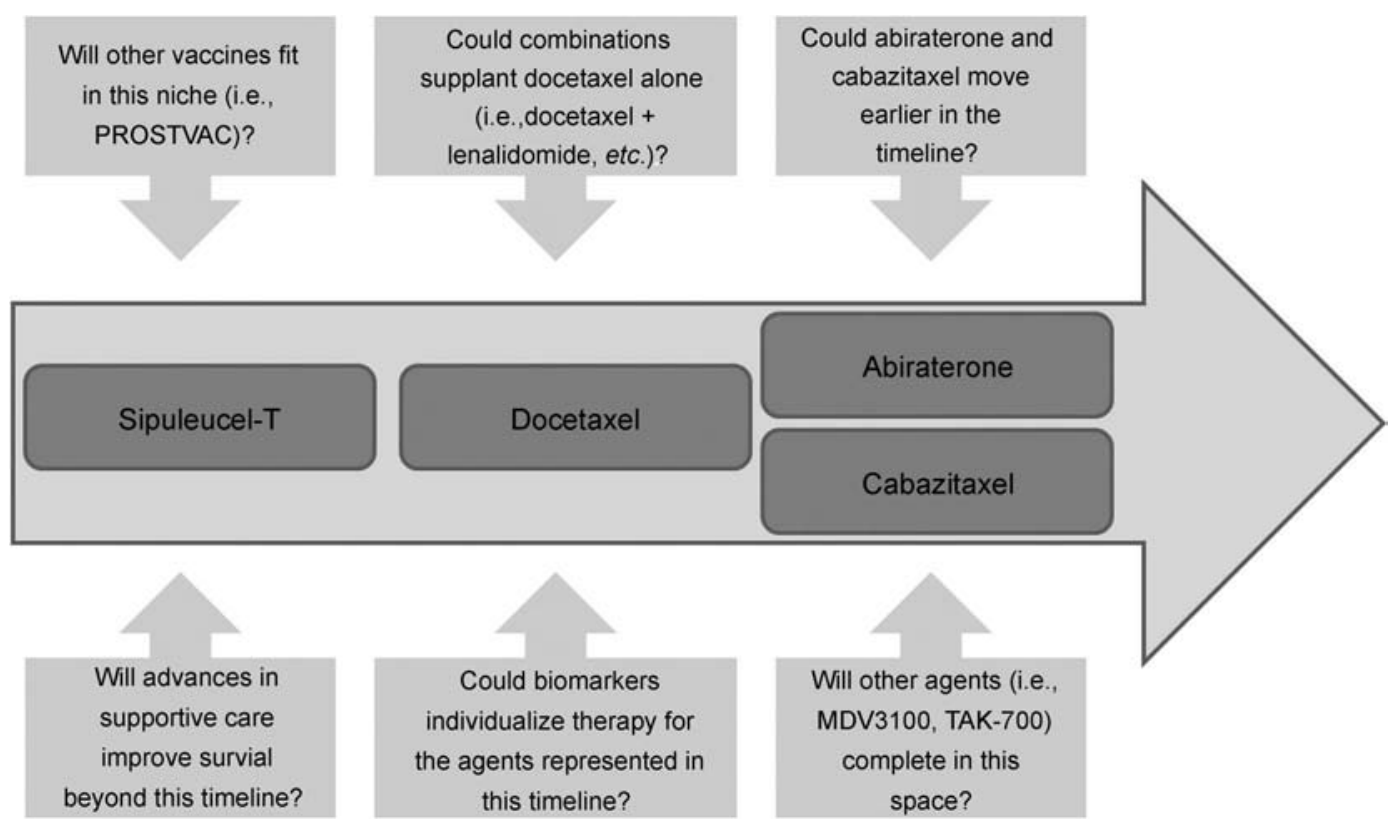

Figure 2 Therapies for metastatic castration-resistant prostate cancer (mCPRC) accounting for the report of positive survival data for sipuleucel-T, abiraterone and cabazitaxel. Relevant clinical questions in the current landscape are posited. 
novel biomarkers exist in the current literature, although they all still require clinical validation. For instance, androgen receptor splice variants are highly expressed in CRPC. ${ }^{65}$ These isoforms lack a ligand binding domain, and may therefore confer resistance to agents such as abiraterone. Another study is examining the role of the TMPRSS2:ERG fusion gene, which modulates expression of ETS family proteins and in turn regulates prostate cancer growth and proliferation, in the context of predicting abiraterone response. ${ }^{66}$ Multiple putative biomarkers exist beyond these two examples, including circulating tumor cells and others-a comprehensive discussion of this topic is beyond the scope of this brief review. Given multiple calls to 'personalize' cancer care, it is imperative that focus be placed on biomarker discovery and validation in the next generation of clinical trials.

These goals notwithstanding, has the prognosis of CRPC improved within the past decade? Although the answer is 'yes', the degree of benefit from individual agents is difficult to quantify. What contributions are attributable to better performance status, better supportive care and various lead time biases versus newer therapeutics is difficult to ascertain underscoring the essential nature of randomized trials both now and in the future. Supportive care is sometimes a neglected aspect of clinical trials. Supportive care is often hard to quantitatively assess, but in certain settings has been clearly shown to have a survival benefit. ${ }^{67}$ Comparative trials are clearly needed for each new agent in development given the wide variations seen in overall survival using historical data.

Both the disease state itself and treatments are simultaneously and rapidly changing. Given the current multiplicity of available therapies, demonstrating a survival benefit in MCRPC for newer agents will increasingly be a challenge. As highlighted earlier in the context of immunotherapy, the oncology may have to look towards new end points in assessing novel therapies, or perhaps turn to old ones. For instance, maintained quality of life is a central goal in the management of prostate cancer, and a demonstrated improvement in this end point led to the approval of mitoxantrone therapy. ${ }^{68-70}$ At present, it remains unclear whether the recently approved agents yield benefit in this regard-no improvement in pain scores was observed with cabazitaxel therapy, and trends in pain scores have not been published for sipuleucel-T or abiraterone. ${ }^{18,24,37}$

In the near future, it will be critical to interrogate current methods of prognostication in MCRPC both in the first- and second-line settings. For instance, the Halabi nomogram has been externally validated and used as a prognostic tool in multiple settings. ${ }^{71}$ However, it is important to recall that this nomogram was developed using a cohort of patients with mCRPC treated on CALGB protocols between 1991 and 2001. None of these patients received contemporary therapeutic regimens and second-line chemotherapy was virtually unheard of at that time. As described herein, even the past 12 months have been marked by notable advances in mCRPC therapy. Given this rapid evolution, re-examination of such prognostic tools is clearly warranted.

\section{COMPETING FINANCIAL INTERESTS}

Sumanta Kumar Pal, MD: Honoraria: Glaxo-Smith-Kline, Pfizer, Sanofi-Aventis, Novartis; research support: Amgen; consulting: Novartis, Genentech; Oliver Sartor, MD: research support: SanofiAventis, Johnson \& Johnson; consulting: Sanofi-Aventis, Johnson \& Johnson, Medivation, Oncogenex and Takeda.

\section{ACKNOWLEDGMENTS}

Dr Pal's efforts are supported by the NIH Loan Repayment Plan (LRP), the CBCRP 15IB-0140 (California Breast Cancer Research Program Junior IDEA
Award) and NIH K12 2K12CA001727-16A1. The authors would also like to acknowledge the generous support of Nancy and Ira Norris.

1 Jemal A, Siegel R, Xu J, Ward E. Cancer statistics, 2010. CA Cancer J Clin 2010; 60: 277-300.

2 US Mortality Data, 1960-2006, US Mortality Vol. 1930-1959. Atlanta, GA: National Center for Health Statistics, Centers for Disease Control and Prevention.

3 Potosky AL, Miller BA, Albertsen PC, Kramer BS. The role of increasing detection in the rising incidence of prostate cancer. JAMA 1995; 273: 548-52.

4 Schroder FH, Hugosson J, Roobol MJ, Tammela TL, Ciatto S et al. Screening and prostate-cancer mortality in a randomized European study. N Engl J Med 2009; 360: 1320-8.

5 Andriole GL, Crawford ED, Grubb RL 3rd, Buys SS, Chia D et al. Mortality results from a randomized prostate-cancer screening trial. N Engl J Med 2009; 360: 1310-9.

6 Ryan CJ, Elkin EP, Small EJ, Duchane J, Carroll P. Reduced incidence of bony metastasis at initial prostate cancer diagnosis: data from CaPSURE ${ }^{\mathrm{TM}}$. Urol Oncol 2006; 24: 396-402.

7 Bolla M, de Reijke TM, van Tienhoven G, van den Bergh AC, Oddens J et al. Duration of androgen suppression in the treatment of prostate cancer. N Engl J Med 2009; 360: 2516-27.

8 Bolla M, Gonzalez D, Warde P, Dubois JB, Mirimanoff RO et al. Improved survival in patients with locally advanced prostate cancer treated with radiotherapy and goserelin. N Engl J Med 1997; 337: 295-300.

9 Tannock IF, Osoba D, Stockler MR, Ernst DS, Neville AJ et al. Chemotherapy with mitoxantrone plus prednisone or prednisone alone for symptomatic hormone-resistant prostate cancer: a Canadian randomized trial with palliative end points. J Clin Oncol 1996; 14: 1756-64.

10 Kantoff PW, Halabi S, Conaway M, Picus J, Kirshner J et al. Hydrocortisone with or without mitoxantrone in men with hormone-refractory prostate cancer: results of the cancer and leukemia group B 9182 study. J Clin Oncol 1999; 17: 2506-13.

11 Petrylak DP, Tangen CM, Hussain MH, Lara PN Jr, Jones JA et al. Docetaxel and estramustine compared with mitoxantrone and prednisone for advanced refractory prostate cancer. N Engl J Med 2004; 351: 1513-20.

12 Tannock IF, de Wit R, Berry WR, Horti J, Pluzanska A et al. Docetaxel plus prednisone or mitoxantrone plus prednisone for advanced prostate cancer. N Engl J Med 2004; 351: 1502-12.

13 Berthold DR, Pond GR, Soban F, de Wit R, Eisenberger M et al. Docetaxel plus prednisone or mitoxantrone plus prednisone for advanced prostate cancer: updated survival in the TAX 327 study. J Clin Oncol 2008; 26: 242-5.

14 Petrylak DP, Tangen CM, Hussain MH, Lara PN Jr, Jones JA et al. Docetaxel and estramustine compared with mitoxantrone and prednisone for advanced refractory prostate cancer. N Engl J Med 2004; 351: 1513-20.

15 Small EJ, Schellhammer PF, Higano CS, Redfern CH, Nemunaitis JJ et al. Placebocontrolled phase III trial of immunologic therapy with sipuleucel-T (APC8015) in patients with metastatic, asymptomatic hormone refractory prostate cancer. J Clin Oncol 2006; 24: 3089-94.

16 Higano CS, Schellhammer PF, Small EJ, Burch PA, Nemunaitis J et al. Integrated data from 2 randomized, double-blind, placebo-controlled, phase 3 trials of active cellular immunotherapy with sipuleucel-T in advanced prostate cancer. Cancer 2009; 115: 3670-9.

17 BLA Teleconference Summary_Provenge, June 26. 2007. http://www.fda.gov/ downloads/BiologicsBloodVaccines/CellularGeneTherapyProducts/ApprovedProducts/ UCM213982.pdf (accessed 29 November 2010)

18 Kantoff PW, Higano CS, Shore ND, Berger ER, Small EJ et al. Sipuleucel-T immunotherapy for castration-resistant prostate cancer. N Engl J Med 2010; 363: 411-22.

19 Provenge Approval Letter. http://www.fda.gov/BiologicsBloodVaccines/CellularGene TherapyProducts/ApprovedProducts/ucm210215.htm (accessed 29 November 2010).

20 Wolchok JD, Hoos A, O'Day S, Weber JS, Hamid O et al. Guidelines for the evaluation of immune therapy activity in solid tumors: immune-related response criteria. Clin Cancer Res 2009; 15: 7412-20.

21 Sheikh NA, Wesley JD, Chadwick E, Perdue N, de Rosa CP et al. Characterization of antigen-specific T-cell activation and cytokine expression induced by sipuleucel-T. J Clin Oncol 2011; 29: Abstr 155.

22 Bissery MC, Bouchard H, Riou J, Vrignaud P, Combeau C et al. Preclinical evaluation of TXD258, a new taxoid. Proc Am Assoc Cancer Res 2000; 41: Abstr 1364.

23 Mita AC, Denis LJ, Rowinsky EK, DeBono JS, Goetz AD et al. Phase I and pharmacokinetic study of XRP6258 (RPR 116258A), a novel taxane, administered as a 1-hour infusion every 3 weeks in patients with advanced solid tumors. Clin Cancer Res 2009; 15: 723-30.

24 de Bono JS, Oudard S, Ozguroglu M, Hansen S, Machiels JP et al. Prednisone plus cabazitaxel or mitoxantrone for metastatic castration-resistant prostate cancer progressing after docetaxel treatment: a randomised open-label trial. Lancet 2010; 376: 1147-54.

25 Pal SK, Sartor AO. Critical appraisal of cabazitaxel in the management of advanced prostate cancer. Clin Interv Aging 2010; 5: 395-402.

26 Huggins C, Hodges CV. Studies on prostatic cancer. I. The effect of castration, of estrogen and of androgen injection on serum phosphatases in metastatic carcinoma of the prostate. Cancer Res $1941 ; 1$ : 293-7. 
27 Huggins C, Stevens RE Jr, Hodges CV. Studies on prostate cancer: II. The effects of castration on advanced carcinoma of the prostate gland. Arch Surg 1941; 43: 209-23.

28 Aragon-Ching JB, Williams KM, Gulley JL. Impact of androgen-deprivation therapy on the immune system: implications for combination therapy of prostate cancer. Front Biosci 2007; 12: 4957-71.

29 Eisenberger M, O'Dwyer P, Friedman M. Gonadotropin hormone-releasing hormone analogues: a new therapeutic approach for prostatic carcinoma. J Clin Oncol 1986; 4: 414-24.

30 Scher H, Liebertz C, Kelly W, Mazumdar M, Brett C, Schwartz L et al. Bicalutamide for advanced prostate cancer: the natural versus treated history of disease. J Clin Oncol 1997: 15: 2928-38.

31 Attard G, Belldegrun AS, de Bono JS. Selective blockade of androgenic steroid synthesis by novel lyase inhibitors as a therapeutic strategy for treating metastatic prostate cancer. BJU Int 2005; 96: 1241-6.

32 Miller WL, Auchus RJ, Geller DH. The regulation of 17,20 lyase activity. Steroids 1997; 62: 133-42.

33 Attard G, Reid AHM, A'Hern R, Parker C, Oommen NB et al. Selective inhibition of CYP17 with abiraterone acetate is highly active in the treatment of castration-resistant prostate cancer. J Clin Oncol 2009; 27: 3742-8.

34 Danila DC, Morris MJ, de Bono JS, Ryan CJ, Denmeade SR et al. Phase II multicenter study of abiraterone acetate plus prednisone therapy in patients with docetaxeltreated castration-resistant prostate cancer. J Clin Oncol 2010; 28: 1496-501.

35 Reid AH, Attard G, Danila DC, Oommen NB, Olmos D et al. Significant and sustained antitumor activity in post-docetaxel, castration-resistant prostate cancer with the CYP17 inhibitor abiraterone acetate. J Clin Oncol 2010; 28: 1489-95.

36 Ryan C, Efstathiou E, Smith M, Taplin M, Bubley G et al. Phase II multicenter study of chemotherapy (chemo)-naive castration-resistant prostate cancer (CRPC) not exposed to ketoconazole (keto), treated with abiraterone acetate (AA) plus prednisone. J Clin Oncol 2009; 27: abstr 5046

37 de Bono JS, Logothetis C, Fizazi K, North S, Chu L et al. Abiraterone acetate plus low dose prednisone improves overall survival in patients with metastatic castrationresistant prostate cancer (CRPC) who have progressed after docetaxel-based chemotherapy: results of COU-AA-301, a randomized double-blind placebocontrolled phase 3 study. Proceedings of the 35th European Society for Medical Oncology (ESMO) Congress; 11 October 2010; Milan, Italy. ESMO: Lugano, Switzerland, 2010. Abstract Number: LBA5.

38 NCT00887198: Abiraterone acetate in asymptomatic or mildly symptomatic patients with metastatic castration-resistant prostate cancer. http://www.clinicaltrials.gov (accessed 29 July 2009).

39 NCT01023061: Phase II trial of radiation with androgen deprivation (RAD) abiraterone acetate, prednisone and LHRH agonist prior to and concurrent with radiation therapy. http://www.clinicaltrials.gov (accessed 15 October 2010).

40 NCT00924469: A phase 2 open-label, randomized, multi-center study of neoadjuvant abiraterone acetate (CB7630) plus leuprolide acetate and prednisone versus leuprolide acetate alone in men with localized high risk prostate cancer. http:// ww.clinicaltrials.gov (accessed 15 October 2010)

41 Kelly WK, Halabi S, Carducci MA, George DJ, Mahoney JF et al. A randomized, doubleblind, placebo-controlled phase III trial comparing docetaxel, prednisone, and placebo with docetaxel, prednisone, and bevacizumab in men with metastatic castration-resistant prostate cancer (mCRPC): survival results of CALGB 90401 J Clin Oncol 2010; 28: abstr LBA4511.

42 Scher HI, Chi KN, de Wit R, Berry WR, Albers P et al. Docetaxel (D) plus high-dose calcitriol versus $D$ plus prednisone $(P)$ for patients ( $P t s$ ) with progressive castrationresistant prostate cancer (CRPC): results from the phase III ASCENT2 trial. J Clin Oncol 2010; 28: 4509.

43 AstraZeneca Website. Results of zibotentan phase III trial in castration resistant prostate cancer. http://www.astrazeneca.com/Media/Press-releases/Article/Results of-Zibotentan-Phase-III-trial-in-castration-resistant-pr (accessed 2 December 2010).

44 NCT00617669: A phase III trial of ZD4054 (zibotentan) (endothelin a antagonist) and docetaxel in metastatic hormone resistant prostate cancer (ENTHUSE M1C). http://www.clinicaltrials.gov (accessed 2 December 2010).

45 NCT00134056: Phase III study of docetaxel and atrasentan versus docetaxel and placebo for patients with advanced hormone refractory prostate cancer. http:/ www.clinicaltrials.gov (accessed 2 December 2010).

46 Carducci MA, Saad F, Abrahamsson PA, Dearnaley DP, Schulman CC et al. A phase 3 randomized controlled trial of the efficacy and safety of atrasentan in men with metastatic hormone-refractory prostate cancer. Cancer 2007; 110: 1959-66.

47 Glinsky GV. Quantitative analysis of circulating tumor cells as a survival predictor in metastatic castration-resistant prostate cancer: missing parts in a superb study. Clin Cancer Res 2009; 15: 1504-5.

48 Keizman D, Zahurak M, Sinibaldi V, Carducci M, Denmeade S et al. Lenalidomide in nonmetastatic biochemically relapsed prostate cancer: results of a phase $1 / 1 \mathrm{I}$ doubleblinded, randomized study. Clin Cancer Res 2010; 16: 5269-76.

49 Mathew P, Tannir N, Tu S, Carter C, Bekele N et al. A modular phase I study of lenalidomide and paclitaxel in metastatic castration-resistant prostate cancer following prior taxane therapy. Cancer Chemother Pharmacol 2010; 65: 811-5.

50 Taneja SS. Circulating tumor cells as a potential efficacy end point in clinical trials of hormone-resistant prostate cancer. Curr Urol Rep 2009; 10: 4-5.

51 Chi KN, Hotte SJ, Yu EY, Tu D, Eigl BJ et al. Randomized phase II study of docetaxel and prednisone with or without OGX-011 in patients with metastatic castrationresistant prostate cancer. J Clin Oncol 2010; 28: 4247-54.
52 Nemunaitis J. Vaccines in cancer: GVAX, a GM-CSF gene vaccine. Expert Rev Vaccines 2005; 4: 259-74.

53 Higano C, Saad F, Somer B, Curti B, Petrylak D et al. A phase III trial of GVAX immunotherapy for prostate cancer versus docetaxel plus prednisone in asymptomatic, castration-resistant prostate cancer (CRPC). Proceeding of the 2009 Genitourinary Cancers Symposium; 26 February 2009; Orlando, FL, USA. ASCO: Alexandria, VA, USA, 2009, Abstr LBA150.

54 Halabi S, Small EJ, Kantoff PW, Kattan MW, Kaplan EB et al. Prognostic model for predicting survival in men with hormone-refractory metastatic prostate cancer. J Clin Oncol 2003; 21: 1232-7.

55 Small E, Demkow T, Gerritsen WR, Rolland F, Hoskin P et al. A phase III trial of GVAX immunotherapy for prostate cancer in combination with docetaxel versus docetaxe plus prednisone in symptomatic, castration-resistant prostate cancer (CRPC). Proceeding of the 2009 Genitourinary Cancers Symposium; 26 February 2009, Orlando, FL, USA. ASCO: Alexandria, VA, USA, 2009, Abstr 7.

56 Kantoff PW, Schuetz TJ, Blumenstein BA, Glode LM, Bilhartz DL et al. Overall survival analysis of a phase ii randomized controlled trial of a poxviral-based PSA-targeted immunotherapy in metastatic castration-resistant prostate cancer. J Clin Oncol2010; 28: 1099-105.

57 Tran C, Ouk S, Clegg NJ, Chen Y, Watson PA et al. Development of a second-generation antiandrogen for treatment of advanced prostate cancer. Science 2009; 324: 787 90.

58 Scher HI, Beer TM, Higano CS, Anand A, Taplin ME et al. Antitumour activity of MDV3100 in castration-resistant prostate cancer: a phase 1-2 study. Lancet 2010 375: $1437-46$.

59 NCT01212991: A safety and efficacy study of oral MDV3100 in chemotherapy-naive patients with progressive metastatic prostate cancer (PREVAIL). http://www. clinicaltrials.gov (accessed 29 November 2010).

60 NCT00974311: AFFIRM: a multinational phase 3, randomized, double-blind, placebo-controlled efficacy and safety study of oral MDV3100 in patients with progressive castration-resistant prostate cancer previously treated with docetaxelbased chemotherapy. http://www.clinicaltrials.gov (accessed 15 October 2010).

61 Vasaitis TS, Bruno RD, Njar VC. CYP17 inhibitors for prostate cancer therapy. J Steroid Biochem Mol Biol; e-pub ahead of print 17 November 2010; doi: 10.1016/j. jsbmb.2010.11.005

62 Dreicer R, Agus DB, MacVicar GR, Wang J, MacLean D et al. Safety, pharmacokinetics, and efficacy of TAK-700 in metastatic castration-resistant prostrate cancer: a phase // II, open-label study. J Clin Oncol 2010; 28: abstr 3084.

63 NCT01193257: Study comparing orteronel plus prednisone in patients with metastatic castration-resistant prostate cancer. http://www.clinicaltrials.gov (accessed 2 December 2010).

64 de Wit R. Chemotherapy in hormone-refractory prostate cancer. BJU Int 2008; 101 (Suppl 2): 11-5

65 Watson PA, Chen YF, Balbas MD, Wongvipat J, Socci ND et al. Constitutively active androgen receptor splice variants expressed in castration-resistant prostate cance require full-length androgen receptor. Proc Natl Acad Sci USA 2010; 107: 1675965

66 Tomlins SA, Rhodes DR, Perner S, Dhanasekaran SM, Mehra R et al. Recurrent fusion of TMPRSS2 and ETS transcription factor genes in prostate cancer. Science 2005 310: 644-8.

67 Temel JS, Greer JA, Muzikansky A, Gallagher ER, Admane S et al. Early palliative care for patients with metastatic non-small-cell lung cancer. N Engl J Med 2010; 363: 733-42.

68 Berthold $\mathrm{DR}$, Pond GR, Roessner $\mathrm{M}$, de Wit $\mathrm{R}$, Eisenberger $\mathrm{M}$ et al. Treatment of hormone-refractory prostate cancer with docetaxel or mitoxantrone: relationships between prostate-specific antigen, pain, and quality of life response and survival in the TAX-327 study. Clin Cancer Res 2008; 14: 2763-7.

69 Berry DL, Moinpour CM, Jiang CS, Ankerst DP, Petrylak DP, et al. Quality of life and pain in advanced stage prostate cancer: results of a Southwest Oncology Group randomized trial comparing docetaxel and estramustine to mitoxantrone and prednisone. J Clin Oncol 2006; 24: 2828-35

70 Osoba D, Tannock IF, Ernst DS, Neville AJ. Health-related quality of life in men with metastatic prostate cancer treated with prednisone alone or mitoxantrone and prednisone. J Clin Oncol 1999; 17: 1654-63.

71 Halabi S, Small EJ, Hayes DF, Vogelzang NJ, Kantoff PW. Prognostic significance of reverse transcriptase polymerase chain reaction for prostate-specific antigen in metastatic prostate cancer: a nested study within CALGB 9583. J Clin Oncol 2003, 21: 490-5.

72 Sartor O, Reid RH, Hoskin PJ, Quick DP, Ell PJ et al. Samarium-153-Lexidronam complex for treatment of painful bone metastases in hormone-refractory prostate cancer. Urology 2004; 63: 940-5.

73 Small EJ, Halabi S, Dawson NA, Stadler WM, Rini BI et al. Antiandrogen withdrawa alone or in combination with ketoconazole in androgen-independent prostate cancer patients: a phase III trial (CALGB 9583). J Clin Oncol 2004; 22: 1025-33.

74 Berry WR, Hathorn JW, Dakhil SR, Loesch DM, Jackson DV et al. Phase II randomized trial of weekly paclitaxel with or without estramustine phosphate in progressive, metastatic, hormone-refractory prostate cancer. Clin Prostate Cancer 2004; 3 104-11.

75 Sternberg CN, Petrylak DP, Sartor O, Witjes JA, Demkow T et al. Multinational, doubleblind, phase III study of prednisone and either satraplatin or placebo in patients with castrate-refractory prostate cancer progressing after prior chemotherapy: the SPARC trial. J Clin Oncol 2009; 27: 5431-8. 